Journal of Sustainable Development of Transport and Logistics

journal home page: https://jsdtl.sciview.net

Prokudin, G., Chupaylenko, O., Dudnik, O., Dudnik, A., \& Pylypenko, Y. (2018). Traveling

salesman problem in the function of freight transport optimization. Journal of Sustainable

Development of Transport and Logistics, 3(1), 29-36. doi:10.14254/jsdtl.2018.3-1.3.

\title{
Traveling salesman problem in the function of freight transport optimization
}

\section{Georgii Prokudin *(D), Olexiy Chupaylenko ** ${ }^{*}$, Olexiy Dudnik ** ${ }^{*}$, Alena

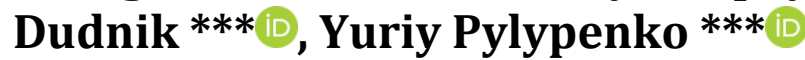

* National Transport University,

1, M. Omelianovycha-Pavlenka Str., Kyiv 01010, Ukraine

Dr., Professor, Department of International Road Transportation and Customs Control

** National Transport University,

1, M. Omelianovycha-Pavlenka Str., Kyiv 01010, Ukraine

PhD, Associate Professor, Department of International Road Transportation and Customs Control

*** National Transport University,

1, M. Omelianovycha-Pavlenka Str., Kyiv 01010, Ukraine

\section{open 0 access cc dol}

\section{Article history:}

Received: January 31, 2017

1st Revision: February 19,

2018

Accepted: March 10, 2018

\section{DOI:}

10.14254/jsdtl.2018.3-1.3

\begin{abstract}
The use of modern information technology means in solving the traveling salesman problem to optimize the routing of freight transportation in international traffic is motivated in this article. The process of solving the traveling salesman problem is automated by modern information technology means, in particular the Delphi Software and the function "Search Solution" in the Microsoft Office Excel table processor. The existing requirements and restrictions on the specificity and dimension of the problem are considered as well.
\end{abstract}

Keywords: Freight, logistics, information technology, traveling salesman problem, closed contour, optimization, route, checkpoint.

\section{Introduction}

Historical reference. In 1859, William Hamilton formulated a problem "Around the World Tour". The problem was focused on finding the shortest route, which would provide one-time visiting of each given settlement and returning to the starting point. The problem gave rise to a new direction in the theory of graphs, known as the search for Hamiltonian cycles in graphs. The Hamiltonian cycle of a graph with $n$ vertices can be represented by the set of pairs of the graph adjacent vertices: $\left\{\left(i_{1}, i_{2}\right) ;\left(i_{2}, i_{3}\right) ; \ldots,\left(i_{n-1}, i_{n}\right) ;\left(i_{n-1}, i_{1}\right)\right\}$.

The problem of the Hamiltonian cycles in the graph theory gained different generalizations (Kozachenko, Vernygora, \& Malashkin, 2015)]. One of these generalizations is the traveling salesman problem, which often occurs in various modifications in transport logistics when planning transportation. The traveling salesman problem is a modified problem of en-route to the destination point; however, in this case, the connection between the points should form a closed cycle.

Corresponding author: Olexiy Chupaylenko

E-mail: dozentalexey@gmail.com

This open access article is distributed under a Creative Commons Attribution (CC-BY) 4.0 license. 
The traveling salesman (came from French, commis voyageur) leaves the first city, visits only once each of $n$ cities and returns to the first city. The distances between cities are known. The challenge is to find a route to cities, which ensures the shortest closed cycle of salesman's travel.

\section{Literature review}

There are several distinct cases of general problem statement, in particular the geometric traveling salesman problem (so-called planar or Euclidean, when the distance matrix reflects the distance between points on a plane), the triangular traveling salesman problem (the triangle inequality occurs on the matrix of values), and the symmetric and asymmetric problems of a traveling salesman. There is also a generalization of the problem, the so-called generalized traveling salesman problem (Kunda, 2008).

Statement of the traveling salesman problem. There are $n$ cities. A matrix of distances $C=\left|C_{i j}\right|$ between them is specified. In the general case, $C_{i j} \neq C_{j i}$. A traveling salesman leaves the first city $A_{0}$, and then visits the other cities one at a time and returns to the city $A_{0}$. Therefore, the route of a traveling salesman is a closed cycle without loops. It is necessary to define the order, in which the city can be driven around to minimize the total traveled distance.

Mathematical model of the problem. Let's introduce the variables: $x_{i j}=1$, if a salesman moves from the city $A_{i}$ to the city $A_{j} ; x_{i j}=0$ - vise versa

where $i, j=1,2, \ldots, n ; i \neq j$. It is necessary to find

$$
\min \sum_{i=0}^{n} \sum_{j=0}^{n} c_{i j} \cdot x_{i j}
$$

under conditions

$$
\begin{aligned}
& \sum_{j=0}^{n} x_{i j}=1 \quad i=1,2, \ldots, n, \\
& \sum_{i=0}^{n} x_{i j}=1 \quad j=1,2, \ldots, n, \\
& u_{i}-u_{j}+n \cdot x_{i j} \leq n-1 \quad i, j=1,2, \ldots, n ; i \neq j .
\end{aligned}
$$

where $u_{i}, u_{j}$ - arbitrary integral nonnegative numbers.

Condition (2) means that a salesman enters each city only once, except for the first one. Condition (3) means that carrier leaves each city only once as well. Condition (4) ensures the closure of the route containing $n$ points, and the absence of loops (Lashenyh, \& Kuzkin, 2006).

Society informatization is a global social process characterized by the fact that the dominant activity in the social production sphere is the collection, accumulation, production, processing, storage, transfer and use of information based on modern microprocessor and computer technology, and various means of information exchange (Prokudin, Danchuk, Tsukanov, \& Tsymbal, 2013).

The importance of information technology application in the transport sector is indisputable. Optimization of freight delivery schemes is very important in the transport industry and logistics (Prokudin, 2006). In most segments of the market, the delivery of goods adds to its value an amount equivalent to the cost of the product itself. In addition, it should be noted that the use of modern information technology for optimization of such delivery leads to minimization of costs, often at least from 5 to $20 \%$ of the product total cost.

This study is mainly focused on the use of modern information technology means in solving the salesman problem to optimize the routing of freight transportation in international traffic. The most important factors that need to be considered in solving the task are: 
- the distances between points of departure and destination, and customs posts;

- time of service at checkpoints (customs clearance);

- time of loading and unloading operations;

- average speed of the vehicle (V);

- time of rest under the European agreement regarding the work of vehicle crews, which perform international automobile transportation (UTRT).

Based on the real data on the locations of points of departure and destination, and checkpoints (CP) across the state border of Ukraine, the distances between them, and average speeds of vehicles, the necessary calculations were made.

\section{Presentation of the main material}

The research was conducted in Zhytomyr region. The wood and wood products make up $23 \%$ of the total exports of the region. Therefore, based on the data analysis of the State Statistics Service of Ukraine, laws and regulations, and the economic and social situation in our country, wooden pellets were selected as over-the-road freight. In Poland the vehicle will be loaded by wooden furniture.

In Zhytomyr region, 10 points of departure were selected: 1) Dubrivka; 2) Romaniv; 3) Liubar; 4) Malyn; 5) Ovruch; 6) Novograd-Volynsky; 7) Zhytomyr, 8) Korosten; 9) Berdychiv; 10) Radomyshl. These places are known to be the largest producers of wooden pellets in the region.

For further research, 2 automobile checkpoints were selected in Volyn region and 6 in Lviv region (Fig. 1). The determining factors for choosing a CP are the time for customs operations and the distance from the places of freight departure. The list of 8 checkpoints at the Ukrainian border is as follows:

1) Yagodyn; 2) Ustylug; 3) Ugryniv; 4) Rava-Ruska; 5) Grushiv; 6) Krakovets; 7) Shegini; 8) Smilnytsa.

Figure 1: Automobile checkpoints at the Ukrainian-Polish border

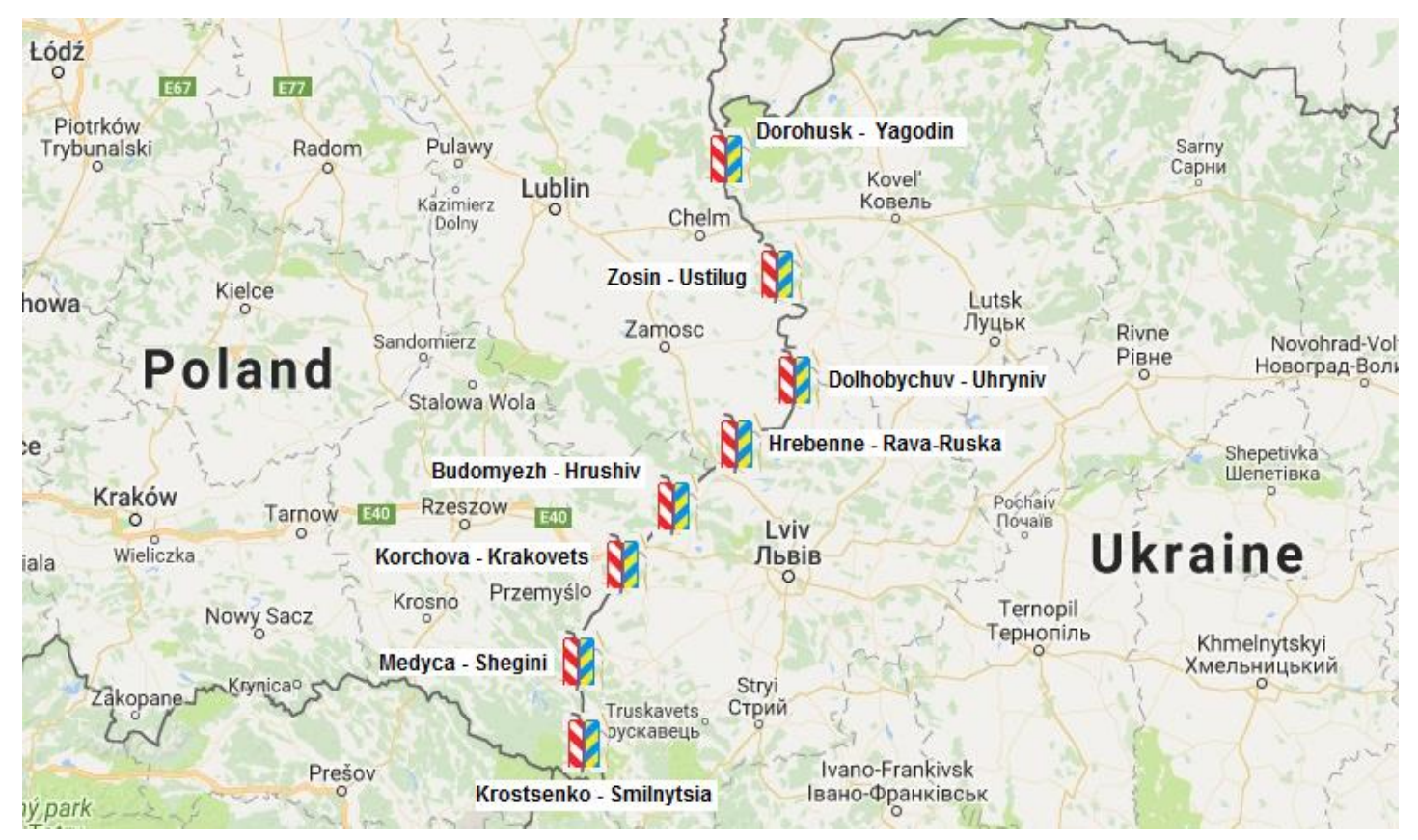

The selected checkpoints in Poland are characterized by the same features as the checkpoints in Ukraine (see Fig. 1), namely:

1) Dorogusk; 2) Zosin; 3) Dolgobychuv; 4) Grebenne; 5) Budomyezh; 6) Korchova; 7) Medyca; 8) Krostsenko.

In Poland, the wooden pellets meet a ready market, and the furniture factories import their finished products to Ukraine. That is why, the selected destination points are as follows: 1) Slupsk; 2) Verushuv; 3) Ratsibuzh; 4) Elblong; 5) Morong; 6) Brodnytsia; 7) Warsaw; 8) Keltse; 9) Ostrovets- 
Sventokshyskyi; 10) Vengruv. In the Microsoft Access database environment, a database was created with appropriate distances between checkpoints, points of departure and destination (Fig. 2).

Figure 2: Database of distances between CPs, points of departure and destination

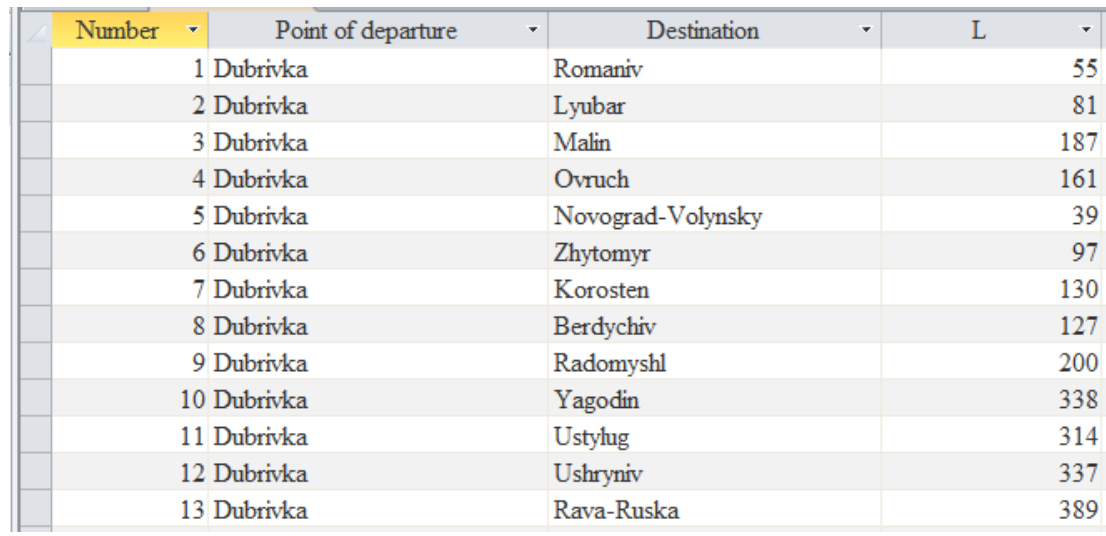

For the convenience of further calculations, data on these distances are automatically reformatted into a Microsoft Excel table processor file, as shown in Fig. 3. The software for solving the traveling salesman problem was designed using the Delphi programming algorithmic language (Johnson, 1990).

Figure 3: Distances between CPs, points of departure and destination in Microsoft Excel file format

\begin{tabular}{|c|c|c|c|c|c|c|c|c|c|c|c|c|c|c|c|c|c|c|c|c|}
\hline 4 & A & B & C & D & $E$ & $\mathrm{~F}$ & G & H & 1 & J & K & L & $\mathrm{M}$ & $\mathrm{N}$ & 0 & $\mathrm{P}$ & Q & $R$ & $S$ & $T$ \\
\hline 1 & & Town & 1 & 2 & 3 & 4 & 5 & 6 & 7 & 8 & 9 & 10 & 11 & 12 & 13 & 14 & 15 & 16 & 17 & 18 \\
\hline 2 & 1 & Dubrivka & 0 & 55 & 81 & 187 & 161 & 39 & 97 & 130 & 127 & 200 & 338 & 314 & 337 & 389 & 432 & 417 & 426 & 455 \\
\hline 3 & 2 & Romaniv & 55 & 0 & 50 & 152 & 182 & 73 & 64 & 136 & 63 & 137 & 381 & 357 & 368 & 443 & 445 & 460 & 457 & 486 \\
\hline 4 & 3 & Lyubar & 81 & 50 & 0 & 174 & 219 & 112 & 84 & 173 & 69 & 157 & 395 & 343 & 329 & 378 & 407 & 393 & 413 & 447 \\
\hline 5 & 4 & Malin & 187 & 152 & 174 & 0 & 94 & 146 & 88 & 58 & 128 & 36 & 404 & 405 & 442 & 508 & 537 & 532 & 557 & 591 \\
\hline 6 & 5 & Ovruch & 161 & 182 & 219 & 94 & 0 & 139 & 133 & 48 & 173 & 127 & 384 & 385 & 422 & 488 & 521 & 505 & 530 & 564 \\
\hline 7 & 6 & Novograd-Volynsky & 39 & 73 & 112 & 146 & 139 & 0 & 84 & 108 & 125 & 157 & 316 & 292 & 307 & 367 & 406 & 395 & 420 & 454 \\
\hline 8 & 7 & Zhytomyr & 97 & 64 & 84 & 88 & 133 & 84 & 0 & 87 & 41 & 74 & 392 & 368 & 403 & 454 & 483 & 471 & 496 & 530 \\
\hline 9 & 8 & Korosten & 130 & 136 & 173 & 58 & 48 & 108 & 87 & 0 & 127 & 90 & 357 & 357 & 394 & 460 & 489 & 474 & 499 & 533 \\
\hline 10 & 9 & Berdychiv & 127 & 63 & 69 & 128 & 173 & 125 & 41 & 127 & 0 & 115 & 433 & 409 & 395 & 431 & 473 & 459 & 484 & 513 \\
\hline 11 & 10 & Radomyshl & 200 & 137 & 157 & 36 & 127 & 157 & 74 & 90 & 115 & 0 & 437 & 437 & 474 & 531 & 559 & 544 & 566 & 600 \\
\hline 12 & 11 & Yagodin (PP) & 338 & 381 & 395 & 404 & 384 & 316 & 392 & 357 & 433 & 437 & 0 & 83 & 120 & 212 & 239 & 256 & 283 & 325 \\
\hline 13 & 12 & Ustylug (PP) & 314 & 357 & 343 & 405 & 385 & 292 & 368 & 357 & 409 & 437 & 83 & 0 & 60 & 148 & 179 & 196 & 218 & 265 \\
\hline 14 & 13 & Ushryniv (PP) & 337 & 368 & 329 & 442 & 422 & 307 & 403 & 394 & 395 & 474 & 120 & 60 & 0 & 103 & 134 & 150 & 173 & 220 \\
\hline 15 & 14 & Rava-Ruska (PP) & 389 & 443 & 378 & 508 & 488 & 367 & 454 & 460 & 431 & 531 & 212 & 148 & 103 & 0 & 32 & 55 & 93 & 162 \\
\hline 16 & 15 & Hrushiv (PP) & 432 & 445 & 407 & 537 & 521 & 406 & 483 & 489 & 473 & 559 & 239 & 179 & 134 & 32 & 0 & 26 & 82 & 151 \\
\hline 17 & 16 & Krakovets (PP) & 417 & 460 & 393 & 532 & 505 & 395 & 471 & 474 & 459 & 544 & 256 & 196 & 150 & 55 & 26 & 0 & 33 & 89 \\
\hline 18 & 17 & Shegini (PP) & 426 & 457 & 413 & 557 & 530 & 420 & 496 & 499 & 484 & 566 & 283 & 218 & 173 & 93 & 82 & 33 & 0 & 57 \\
\hline 19 & 18 & Smilnytsia (PP) & 455 & 486 & 447 & 591 & 564 & 454 & 530 & 533 & 513 & 600 & 325 & 265 & 220 & 162 & 151 & 89 & 57 & 0 \\
\hline
\end{tabular}

To begin with, a page to entry the input data for further calculations is developed, namely the time characteristics of loading and unloading operations in this route. The process of loading and unloading pallets and furniture is mechanized. The time of service in the $\mathrm{CP}$ and the average technical speed of the vehicle are set $\left(V_{t}=65 \mathrm{~km} / \mathrm{h}\right)$.

Let's consider an example of the traveling salesman problem with 1 point of departure in Ukraine, 4 CPs (two in Ukraine and two in Poland), 4 destination points in Poland. That is, in one of the cities of Zhytomyr region, 20 tons of wooden pellets are loaded. The process of loading is mechanized. In each 4 cities of Poland, 5 tons of freight are unloaded (20 tons in total); and in the last city, 20 cubic meters of furniture are loaded (also approximately 20 tons). Both wooden pellets and furniture belong to the $1^{\text {st }}$ class of goods, that is, the coefficient of static use of the vehicle carrying capacity is equal to $\left(\gamma_{\mathrm{cm}}=1\right)$. It should be noted that the program works in two modes, manual and automatic. That is, CPs can be selected independently, or the program does it automatically, selecting the closest ones to the point of departure. 
The program generates a table, which clearly shows the distances between the specified cities and the CPs. It allows finding possible closed routes and choosing the shortest of all variants (Fig. 4).

\section{Figure 4: Result of the program work}

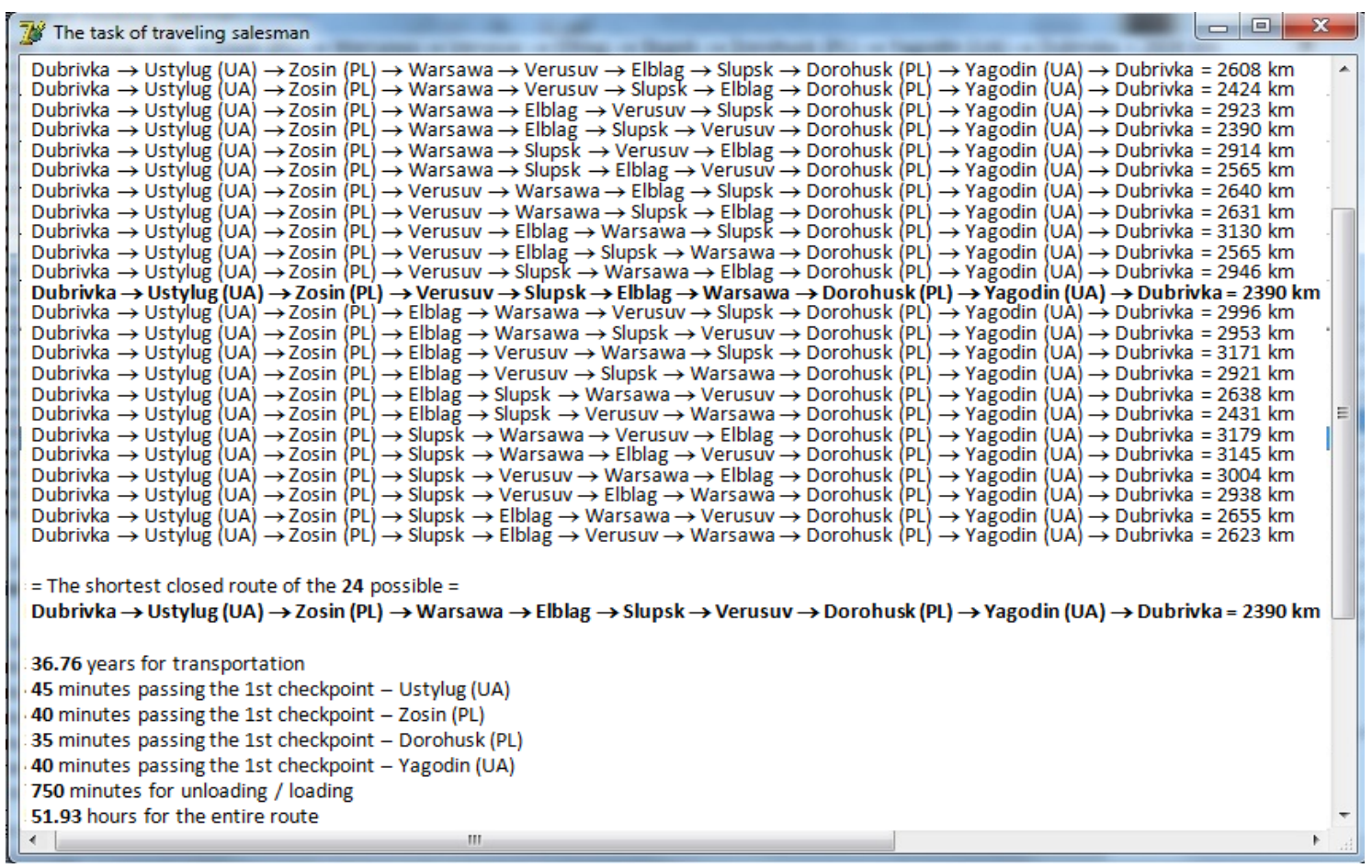

Based on the combinatorial method (Prokudin, 2014), the program automatically calculates the total distance of the route and selects the one where the distance between the cities is the shortest. Map of the specified route is presented in Fig. 5.

Figure 5: Map of a defined closed route

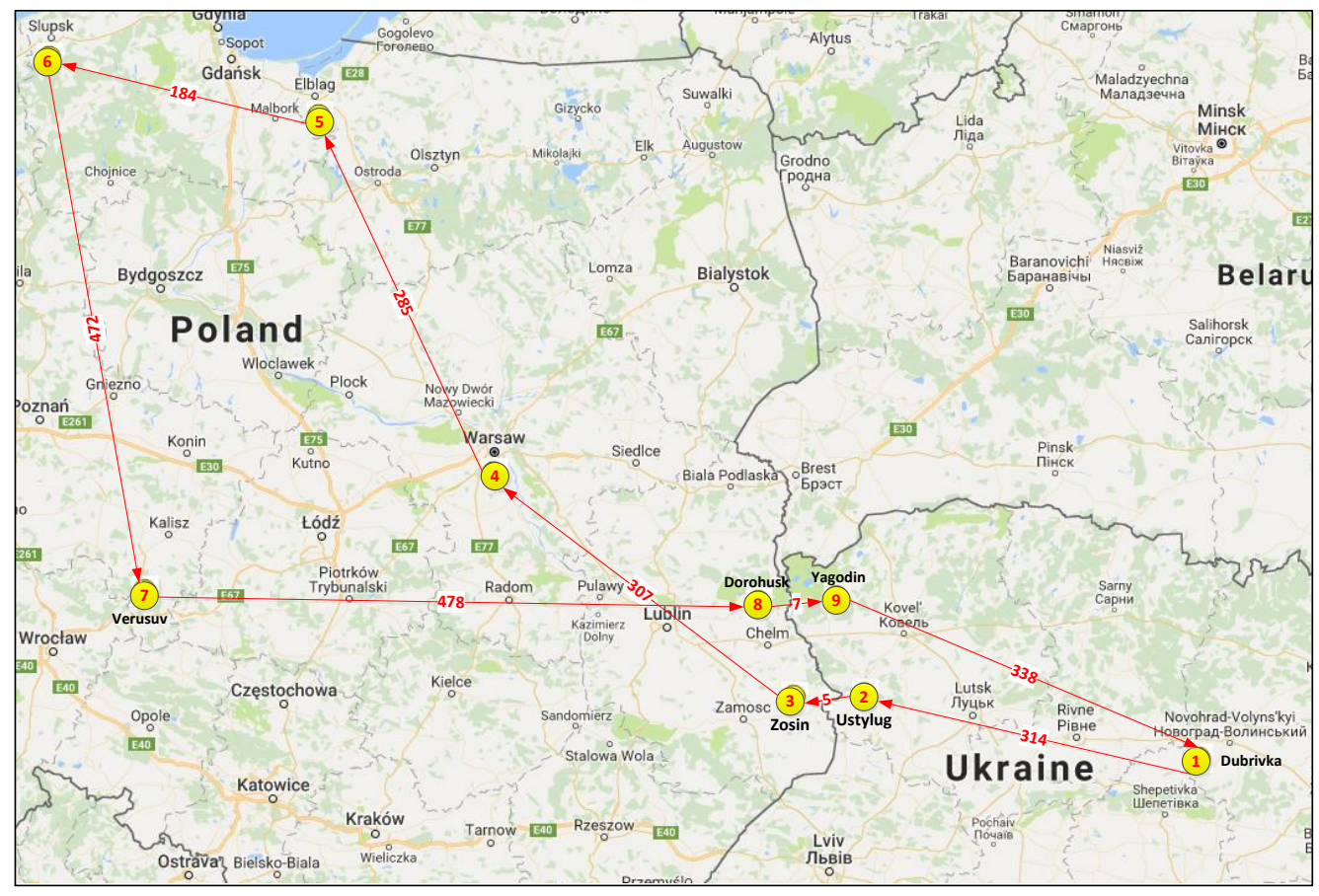

Thus, the program identified 24 possible routes; the route Dubrivka (Ukraine) $\rightarrow$ Ustylug (CP, Ukraine) $\rightarrow$ Zosin $($ CP, Poland) $\rightarrow$ Warsaw (Poland) $\rightarrow$ Elblong (Poland) $\rightarrow$ Slupsk (Poland) $\rightarrow$ Verushuv 
(Poland) $\rightarrow$ Dorogusk (CP, Poland) $\rightarrow$ Yagodyn (CP, Ukraine) $\rightarrow$ Dubrivka (Ukraine) was considered the most effective one. The length of the route is $2390 \mathrm{~km}$. The total time of transportation is $36.76 \mathrm{~h}$, the time of service at the first CP (Ustylug) - $45 \mathrm{~min}$, at the second CP (Zosin) - $40 \mathrm{~min}$, in the third CP (Dorogusk) - $35 \mathrm{~min}$, in the fourth CP (Yagodyn) - $40 \mathrm{~min}$. The time expenditure for loading and unloading - $760 \mathrm{~min}$. Based on the above timing data, the total time to complete the route with exception of time characteristics for the driver's sleep is $52.10 \mathrm{~h}$ (according to UTRT).

A detailed analysis of applying the model of the optimal purpose to solve the traveling salesman problem has shown that in this model, in addition to $\mathrm{n}$ ! Hamiltonian (full) contours, there are also many incomplete (isolated) contours that cover only certain groups of cities. This fact greatly complicated the solving of the traveling salesman problem and made the researchers look for other more effective methods of its solution.

Further, an example of the traveling salesman problem solution for $n=9$ (1 city-supplier in Ukraine, 2 CPs in Ukraine, 2 CPs in Poland, 4 city-consumers in Poland) in the Microsoft Office Excel spreadsheet using the Search Solution function is presented (Kuzmychov \& Medvediev, 2005). We select the same CPs and cities, as in the previous example.

In Fig. 6, an Excel spreadsheet with source data (distances) between cities is shown. However, to solve the traveling salesman problem for any (and fully oriented) graphs, the absence of an arc between nodes in the transport correspondence matrix should be designated by the infinity $V_{i j}=\infty$. It means that the numbers of 2-3 orders of magnitude larger than the maximum distance should be entered in these cells, namely, in our case, the number is assumed to be equal to 99999.

Figure 6: Starting matrix of distances between cities

\begin{tabular}{|c|c|c|c|c|c|c|c|c|c|c|}
\hline 4 & A & B & C & D & $E$ & $\mathrm{~F}$ & G & H & I & J \\
\hline 1 & & Dubrivka & Yagodin & Ustylug & Dorohusk & Zosin & Warsawa & Verusuv & Elblag & Slupsk \\
\hline 2 & Dubrivka & 99999 & 338 & 314 & 99999 & 99999 & 99999 & 99999 & 99999 & 99999 \\
\hline 3 & Yagodin & 338 & 99999 & 99999 & 7 & 99999 & 99999 & 99999 & 99999 & 99999 \\
\hline 4 & Ustylug & 314 & 99999 & 99999 & 99999 & 5 & 99999 & 99999 & 99999 & 99999 \\
\hline 5 & Dorohusk & 99999 & 7 & 99999 & 99999 & 99999 & 270 & 478 & 539 & 734 \\
\hline 6 & Zosin & 99999 & 99999 & 5 & 99999 & 99999 & 307 & 515 & 583 & 786 \\
\hline 7 & Warsawa & 99999 & 99999 & 99999 & 270 & 307 & 99999 & 313 & 285 & 471 \\
\hline 8 & Verusuv & 99999 & 99999 & 99999 & 478 & 515 & 313 & 99999 & 461 & 472 \\
\hline 9 & Elblag & 99999 & 99999 & 99999 & 539 & 583 & 285 & 461 & 99999 & 184 \\
\hline 10 & Slupsk & 99999 & 99999 & 99999 & 734 & 786 & 471 & 472 & 184 & 99999 \\
\hline
\end{tabular}

The process of calculating the traveling salesman problem in Excel includes the following steps: inputting the initial data (see Fig. 6); forming a matrix, where the sum of elements in rows and columns is calculated; forming a constraint matrix of consistency and a target function; forming a model of the optimization problem; obtaining the final result (Fig. 7).

Figure 7. Obtaining the final result

\begin{tabular}{|c|c|c|c|c|c|c|c|c|c|c|c|}
\hline 12 & & Dubrivka & Yagodin & Ustylug & Dorohusk & Zosin & Warsawa & Verusuv & Elblag & Slupsk & Out \\
\hline 13 & Dubrivka & 0 & 1 & 0 & 0 & 0 & 0 & 0 & 0 & 0 & 1 \\
\hline 14 & Yagodin & 0 & 0 & 0 & 1 & 0 & 0 & 0 & 0 & 0 & 1 \\
\hline 15 & Ustylug & 1 & 0 & 0 & 0 & 0 & 0 & 0 & 0 & 0 & 1 \\
\hline 16 & Dorohusk & 0 & 0 & 0 & 0 & 0 & 0 & 1 & 0 & 0 & 1 \\
\hline 17 & Zosin & 0 & 0 & 1 & 0 & 0 & 0 & 0 & 0 & 0 & 1 \\
\hline 18 & Warsawa & 0 & 0 & 0 & 0 & 1 & 0 & 0 & 0 & 0 & 1 \\
\hline 19 & Verusuv & 0 & 0 & 0 & 0 & 0 & 0 & 0 & 0 & 1 & 1 \\
\hline 20 & Elblag & 0 & 0 & 0 & 0 & 0 & 1 & 0 & 0 & 0 & 1 \\
\hline 21 & Slupsk & 0 & 0 & 0 & 0 & 0 & 0 & 0 & 1 & 0 & 1 \\
\hline 22 & In & 1 & 1 & 1 & 1 & 1 & 1 & 1 & 1 & 1 & \\
\hline 36 & Ta! & get funct & ion & 2390,0 & & & & & & & \\
\hline
\end{tabular}

Consequently, based on the calculations in the Excel table processor, an optimal closed route of freight transportation is obtained (Fig. 8). 
Figure 8: Presentation of the optimal transportation route on the map

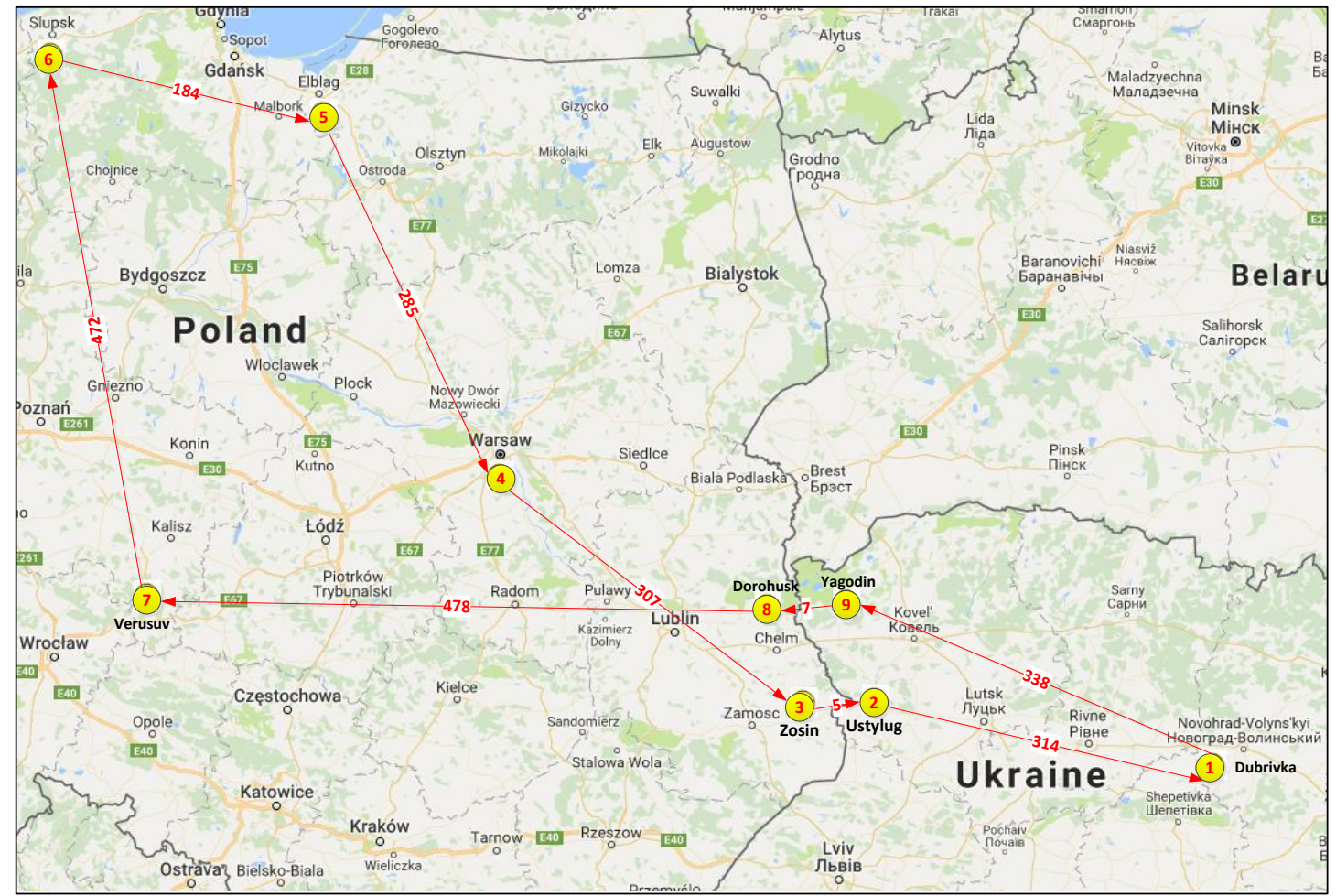

The length of the calculated route (Dubrovka $\rightarrow$ Yagodyn $\rightarrow$ Dorogusk $\rightarrow$ Warsaw $\rightarrow$ Elblong $\rightarrow$ Slupsk $\rightarrow$ Verushuv $\rightarrow$ Zosin $\rightarrow$ Ustylug $\rightarrow$ Dubrovka) is $2390 \mathrm{~km}$. It should be noted that in two variants of solving this task (using the Delphi software environment and the Excel spreadsheet), the same length of the route $2390 \mathrm{~km}$ is calculated, although the sequence of passing cities in both variants is different.

\section{Conclusion}

During this study, the use of the Delphi Software and the function "Search Solution" in the Microsoft Office Excel table processor in solving the traveling salesman problem to optimize the routing of freight transportation in international traffic is motivated in this article. The existing requirements and restrictions on the specificity and dimension of the problem are considered as well.

\section{Appendix A. Supplementary material}

Supplementary data associated with this article can be found, in the online version, at https://jsdtl.sciview.net

\section{Funding}

The authors received no direct funding for this research.

\section{Citation information}

Prokudin, G., Chupaylenko, O., Dudnik, O., Dudnik, A., \& Pylypenko, Y. (2018). Traveling salesman problem in the function of freight transport optimization. Journal of Sustainable Development of Transport and Logistics, 3(1), 29-36. doi:10.14254/jsdtl.2018.3-1.3.

\section{References}

Kozachenko, D., Vernygora, P., \& Malashkin, V. (2015). Fundamentals of operations research in transport systems: Examples and tasks. DNUZT Publ. (in Ukrainian).

Kunda, N. (2008). Operations research in transport systems. Vydavnychyi Dim “Slovo” Publ. (in Ukrainian). 
Lashenykh, O., \& Kuzkin, O. (2006). Methods and models of optimization of transport processes and systems. ZNTU Publ. (in Ukrainian).

Prokudin, G., Danchuk, V., Tsukanov, O., \& Tsymbal, N. (2013). Computer technology statistical analysis of transport. NTU Publ. (in Ukrainian).

Prokudin, G. (2006). Models and methods of optimization of transportation in transport systems. NTU Publ. (in Ukrainian).

Johnson, D. (1990). Local Optimization and the Traveling Salesmen Problem. Springer-Verlag, 446-461. (in Russian).

Prokudin, O. (2014). Information technology functioning transport logistics Production Enterprise. Informatsiini protsesy, tekhnologii ta systemy, 1, 38-49 (in Ukrainian).

Kuzmychov, A., \& Medvediev, M. (2005). Mathematical Programming in Excel. EU Publ. (in Ukrainian).

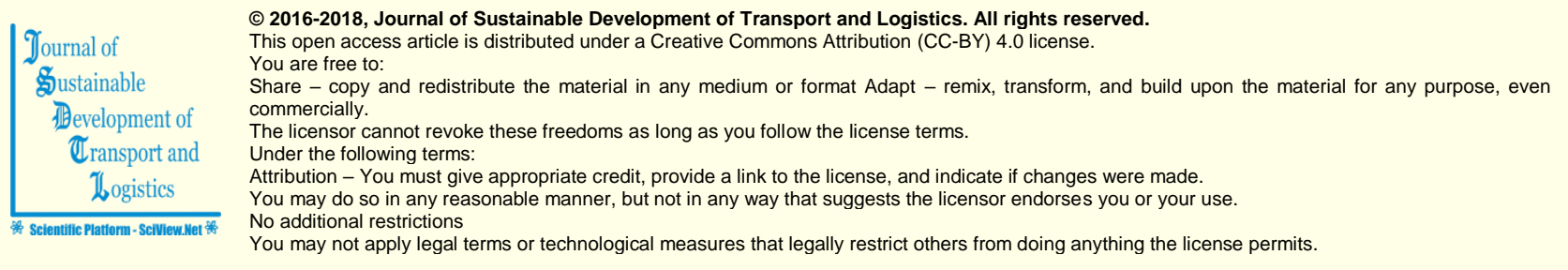

Journal of Sustainable Development of Transport and Logistics (ISSN: 2520-2979) is published by Scientific Publishing House "CSR", Poland, EU and Scientific Publishing House "SciView", Poland, EU

Publishing with JSDTL ensures:

- Immediate, universal access to your article on publication

- High visibility and discoverability via the JSDTL website

- Rapid publication

- Rapid publication

- Discounts and waivers for authors in developing regions

Submit your manuscript to a JSDTL at https://jsdtl.sciview.net/ or submit.jsdt|@sciview.net 